\title{
A PERSPECTIVA EVOLUCIONISTA SOBRE RELAÇÕES ROMÂNTICAS'
}

\author{
Victor Kenji M. Shiramizu \\ Fívia de Araújo Lopes
}

Resumo: As relações românticas possuem um forte impacto no nosso cotidiano.Todavia, a compreensão do motivo pelo qual alguns relacionamentos românticos duram mais do que outros se torna mais consistente integrando perspectivas biológicas e sociais. Este trabalho tem como objetivo revisar de forma crítica os conceitos sobre Amor, Teoria do Apego e as Estratégias Sexuais a partir de uma perspectiva evolucionista, a fim de contribuir com a revisão para a literatura no Brasil. As lacunas observadas sobre a temática conjuntamente com resultados obtidos em algumas pesquisas em nosso país são encorajadores para a manutenção da integração teórica na área de pesquisa, que pode ser aplicada na orientação de casais, contribuindo para a satisfação dentro dos relacionamentos românticos.

Palavras-chave: Amor. Teoria do Apego. Estratégias Sexuais. Perspectiva Evolucionista.

\section{Por que estudar amor?}

Diariamente somos expostos a diversos tipos de relações interpessoais. Dentre elas, as relações românticas levam-nos a agir de diferentes maneiras, e nos colocam diante de várias questões. Por exemplo, quando uma interação ocasional (popularmente conhecida como "ficada") transforma-se em um relacionamento de longo prazo? Que fatores podem estar por trás dessa decisão? Por que alguns rela-

1 Gostaríamos de agradecer as contribuições e valiosos comentários de Felipe N. Castro, Marcus André V. Vasconcelos, Maria de Fátima Arruda e Wallisen T. Hattori durante a elaboração desta revisão, a qual é derivada da dissertação de mestrado do primeiro autor com orientação da segunda autora. 
cionamentos são superficiais e há outros em que os parceiros estão fortemente comprometidos? Que mecanismos favorecem o apego por uma determinada pessoa?

Claramente não são respostas simples, sobretudo quando consideramos pesquisas sistemáticas que possam abranger todos esses aspectos. Apesar de ser um tema estimulante, as revisões críticas sobre os relacionamentos românticos podem ser consideradas escassas no Brasil. Realizando buscas nas bases de dados LILACS e SciELO, sem limitar o ano de publicação, pelas palavras "relacionamentos amorosos",'relacionamentos românticos","relações amorosas" e "relações românticas" foram recuperados 78 resultados, dos quais nenhum deles enquadrou-se na perspectiva evolucionista adotada na presente revisão teórica (Tabela 1).

Tabela 1

Resultados recuperados na busca pelas palavras-chave nas bases de dados LILACS e SciELO em janeiro de 2012

\begin{tabular}{ccc}
\hline Palavra chave & LILACS & SciELO \\
\hline Relacionamentos amorosos & 19 & 13 \\
Relacionamentos românticos & 1 & 0 \\
Relações amorosas & 42 & 0 \\
Relações românticas & 3 & 0 \\
\hline Total & 78 & \\
\hline
\end{tabular}

No presente trabalho, revisaremos conceitos de amor, as tipologias que o envolvem, o apego e as estratégias sexuais, a partir de uma perspectiva evolucionista, como uma forma de articular teorias biológicas e sociais no que diz respeito às relações românticas. Além disso, sugerimos alguns tópicos que podem ser potenciais aspectos a serem investigados nessa área de pesquisa que está em crescimento no nosso país.

\section{O amor como objeto de ciência}

José de Alencar, um dos notáveis da literatura brasileira, escreveu em seu romance Cinco Minutos:"o amor não compreende esses cálculos e esses raciocínios próprios da fraqueza humana; criado com uma partícula do fogo divino, ele eleva o homem acima da terra" (Alencar, 1870/1997, p. 19). Neste trecho, o romancista trata o amor como algo supremo, forte o suficiente para fazê-lo perder a razão. 
A presença do amor na história da humanidade pode ser datada desde a antiguidade até os dias atuais através da literatura, ora como uma típica história romântica, ora como uma história fatídica (Fisher, 2006; Hendrick \& Hendrick, 2006). Segundo Harlow (1958), a natureza do amor proporciona às pessoas o sentimento de recompensa. Sternberg e Grajek (1984) destacam que o amor leva as pessoas a mentir, enganar, roubar e até matar em seu nome. Mas que sentimento seria esse que leva a caminhos tão distintos?

Os estudos sistemáticos iniciais sobre amor sempre estiveram no âmbito da perspectiva social, notadamente no campo da psicologia social e da personalidade, e uma das grandes dificuldades era de como defini-lo. Por exemplo, Harlow (1958) define amor como um estado maravilhoso, profundo, delicado e gratificante. Rubin (1970) define amor como sendo "uma atitude que uma pessoa direciona a outra em particular, envolvendo predisposições a pensar, sentir e se comportar de certas formas em relação a esta outra pessoa" (p. 265). Fehr $(1988,2006)$ defende que amor é um conceito que não pode ser definido classicamente, por ter sido construído em torno dos exemplos mais claros, tendo, portanto, uma abordagem prototípica². Ainda, Beall e Sternberg (1995) sugerem que essa definição é difícil ou até mesmo impossível. Segundo eles, indivíduos de culturas diferentes experimentam o amor diferentemente, porque o amor seria construído socialmente, um constructo multidimensional que inclui comportamentos, sentimentos e pensamentos. Portanto, o amor seria uma experiência emocional que muda de acordo com o ambiente social. Embora valiosos esforços tenham sido feitos no intuito de definir "amor", Shaver e Mikulincer (2006) pontuam que esses estudos iniciais, dentro da perspectiva social, adotavam uma abordagem descritiva e ateórica, chegando a conclusões errôneas, como por exemplo, de que o amor foi uma "invenção" da cultura ocidental. Todavia, esses estudos não discutiam que funções (no sentido evolutivo) o amor teria no cotidiano das pessoas.

Diferentemente da abordagem utilizada pelos autores anteriormente citados, Buss (1988), utilizando uma perspectiva evolucionista, sugere que o amor é mais do que um estado, ele pode ser visto como atos, os quais, no passado, teriam servido a funções ligadas ao sucesso reprodutivo do indivíduo. Dentre essas funções, o autor destaca a escolha de parceiros e a reprodução como os objetivos centrais desses atos de amor. Nessa mesma perspectiva, Fisher et al. (2002), utilizando evidências de estudos em animais não-humanos e em humanos, propõem que vias neurais específicas e extremamente interligadas, envolvidas com o amor romântico, foram selecionadas ao longo da história evolutiva de mamífe-

2 A abordagem prototípica foi proposta por Rosch (1975) para explicar como determinados conceitos precisam valer-se de exemplos chave, os quais remetem aos melhores elementos dentro da categoria em questão e não propriamente às suas definições. 
ros. Essas vias, quando ativadas por monoaminas (dopamina, por exemplo) e/ou hormônios (ocitocina, por exemplo), promovem a busca por parceiros românticos, a expressão de comportamentos característicos do amor romântico e a formação de vínculos emocionais entre parceiros românticos, favorecendo, assim, a reprodução.

Considerando perspectivas sociais e biológicas, acreditamos que isoladamente, nenhuma delas consegue contemplar o fenômeno do amor, que para nós inclui comportamentos, sentimentos e pensamentos selecionados ao longo de nossa história evolutiva que favoreceu a vinculação de parceiros, promovendo uma aproximação e um investimento diferenciado de tempo e atenção entre estes que pode variar de acordo com as condições ecológicas, sociais e culturais.

\section{Tipologias do Amor}

O amor que dirigimos a diferentes pessoas é o mesmo amor? Quando nos referimos ao amor pela nossa mãe e ao amor por um parceiro romântico, estamos falando do mesmo sentimento? Essa foi uma das perguntas que motivaram o surgimento de diversas teorias no intuito de ir além da simples conceitualização de amor, e buscaram identificar e compreender os possíveis tipos de amor (Berscheid, 2006; Fehr, 2001).

Ao contrário do que pesquisadores de sua época fizeram, John Alan Lee "fugiu" da definição de amor e começou o estudo dos estilos de amor, publicando o livro The Colors of Love: An Exploration of the Ways of Loving em 1973, uma tipologia utilizada por vários outros autores (entre eles Fehr, 2006; Hegi \& Bergner, 2010; Hendrick \& Hendrick, 1986). Lee compara o amor com cores, afirmando que se torna muito mais interessante discutir a preferência de cor (estilos de amor) que cada pessoa tem do que fazer uma simples definição do que é cor (definição de amor) (Lee, 1988). Através de dados obtidos em entrevistas com aproximadamente duzentas pessoas, Lee observou que cada história era única, mas que existiam características comuns entre elas quando agrupadas, surgindo dois principais grupos de amor: um grupo primário no qual estão incluídos os estilos Eros (caracterizado pela busca da pessoa amada, cuja imagem já está representada na mente do amante), Ludus (estilo de amor em que o amante "coleciona" experiências, as quais são lembradas com prazer) e Storge (o amor como amizade, onde os parceiros acostumam-se um com o outro); e um grupo secundário: Mania (caracterizado pelo ciúme, pela obsessão e maior intensidade emocional), Agape (estilo sacrificante, no qual o bem estar da pessoa amada é colocado acima de tudo) e Pragma (um estilo de amor racional, em que as decisões são tomadas mais pela razão do que pela emoção) (Fehr \& Russel, 1991; Gouveia, Fonseca, Caval- 
canti, Diniz, \& Dória, 2009; Hendrick \& Hendrick, 1986). Hendrick e Hendrick (2006) ressaltam a importância de Lee analisar o amor como estilos ao invés de uma ideologia, pois estilos são construídos de forma interacional e um indivíduo pode ter mais de um estilo com parceiros diferentes.

Outra grande contribuição para compreender os diferentes tipos de amor foi a Teoria Triangular do Amor de Robert J. Sternberg publicada em 1986. Sternberg propõe que o amor pode ser visto como um triângulo, no qual cada vértice corresponde a um componente do amor, a saber: intimidade, paixão e decisão/comprometimento.

O componente intimidade faz referência aos sentimentos que promovem proximidade, vinculação e conectividade (Sternberg, 1986; 1988; 1997; 2006). A importância da intimidade está no fato dela ser o alicerce do amor, entretanto esse alicerce desenvolve-se de forma lenta e é difícil de ser alcançado, pois é necessário "quebrar"o muro que separa uma pessoa da outra (Sternberg, 1988).

Os fenômenos relacionados às relações românticas tais como romance, atração física e amor consumado são todos conduzidos pelo componente paixão. Este componente nas relações românticas possui a função de provocar e motivar a experiência da paixão nas relações (Sternberg, 1986).

O componente decisão/comprometimento consiste de dois aspectos: a curto prazo, a decisão de amar ou não uma pessoa; a longo prazo, o comprometimento de manter ou não a relação com esta pessoa. A decisão e o comprometimento não necessariamente ocorrem juntos (Sternberg, 1988).

De acordo com essa teoria, através das diferentes combinações e as interrelações desses três componentes seria possível obter oito tipos de amor, como por exemplo, o amor romântico que é derivado da combinação entre os componentes intimidade e paixão; esse tipo de amor não inclui apenas a atração física, mas os indivíduos envolvidos na relação estão vinculados emocionalmente, mas a priori sem nenhum comprometimento (para detalhes sobre os outros tipos de amor, ver Sternberg, 1986).

Um dos pontos fortes da teoria Triangular do Amor é a contribuição que Sternberg trouxe da Psicologia Cognitiva, principalmente no que diz respeito ao processo cognitivo básico de percepção. De um modo geral, pode-se dizer que o indivíduo, através de experiências em relacionamentos anteriores, "organiza" o que ele espera do parceiro dentro da relação atual, levando-se em conta que o outro também apresenta expectativas com relação ao parceiro. Isso pode gerar, por um lado, conflitos dentro dessa relação uma vez que um dos lados pode não se sentir correspondido, e por outro pode ser preditivo de satisfação dentro da relação caso as expectativas do que o indivíduo espera sejam "atingidas".

Sternberg e Barnes (1985) já haviam analisado as "duas faces da moeda" com casais de universitários que responderam o que um sentia sobre o outro e o que um acreditava que o outro sentia sobre ele. Os 
autores concluíram que não é a ausência de um parceiro ideal por si só que leva à insatisfação do relacionamento, mas sim a diferença percebida pelo indivíduo entre o parceiro ideal e o parceiro atual.

No entanto, apesar de bem fundamentada, por enfocar o aspecto perceptual da relação com o parceiro, sobretudo com base em relacionamentos anteriores, a proposta da teoria Triangular do Amor não oferece um elemento de referência, que as pessoas tomariam como ponto de partida, um protótipo, para os seus relacionamentos. Diante de tal necessidade, em 1997, o próprio Sternberg propõe que a teoria Triangular do Amor deveria ser associada com outras teorias, como por exemplo, a Teoria do Apego, para favorecer uma melhor compreensão quanto ao amor e às relações interpessoais (Madey \& Rogers, 2009; Sternberg, 1997).

\section{Teoria do Apego}

Até a década de 50 acreditava-se que o infante vinculava-se à mãe somente pelo fato dela ser capaz de fornecer alimento. Essa teoria, conhecida como teoria do amor interesseiro das relações objetais, dominava os escritos psicanalíticos, até a publicação dos estudos de Harry Harlow com macacos rhesus e o artigo de John Bowlby (ambos de 1958) que começaram a mudar tal perspectiva.

Em sua trilogia Apego e Perda, John Bowlby (1969/2002; 1973/2004; 1980/1998) combinou ideias da psicanálise, da teoria dos sistemas de controle e da etologia, propondo que humanos são capazes de desenvolver vínculos emocionais durante o primeiro ano de vida através do sistema comportamental de apego. Esse sistema teria sido moldado pela seleção natural, durante o Ambiente de Adaptação Evolutiva (AAE) de nossa espécie, para promover segurança e aumentar as chances de sobrevivência do indivíduo (Fraley \& Shaver, 2000; George \& West, 2001; Mikulincer \& Shaver, 2008; Schmitt, 2008). Suas observações vieram de crianças criadas em orfanatos que sofreram perda materna e, posteriormente, tornaram-se mais susceptíveis à depressão e a desenvolverem problemas comportamentais e/ou emocionais (Chisholm, 1996).

Através das diversas interações com o cuidador principal, o infante é capaz de elaborar modelos funcionais de si e do outro, os quais perdurarão ao longo da vida. O primeiro modelo refere-se a quanto o indivíduo acredita ser ou não aceitável aos olhos da figura de apego. Já o modelo funcional do outro diz respeito a quanto o indivíduo acredita que a figura de apego estará disponível e receptiva quando for necessário (Bowlby, 1973/2004). Essa figura de apego servirá tanto como base segura (secure base), a partir da qual o infante se sentirá seguro para explorar o ambiente, bem como refúgio seguro (safe haven), nos momentos em que ele se 
sentir angustiado ou assustado durante a exploração (Chisholm, 1996; Collins \& Feeney, 2000).

Quando a teoria foi proposta, entretanto, diversas críticas surgiram, sobretudo quanto à dificuldade de testá-la empiricamente. A entrada da pesquisadora Mary Ainsworth na equipe de Bowlby foi um marco para que essa questão pudesse ser respondida. Ainsworth, Blehar, Waters e Wall (1978) desenvolveram um procedimento denominado de Situação Estranha, o qual é estruturado em um ambiente de laboratório e é composto por oito episódios que têm como objetivo ativar, de forma gradativa, o sistema comportamental de apego do infante baseado em duas separações da mãe, juntamente com a presença de um estranho. Ainsworth e colaboradores observaram que as crianças que participaram dessas situações apresentavam comportamentos permitindo classificá-las de três maneiras: como seguramente apegadas ou inseguramente apegadas (ansiosamente ou evitativamente) (Ainsworth et al., 1978).

Alguns anos mais tarde, pesquisadores da Universidade de Berkeley se depararam com a dificuldade de classificar o padrão de apego observado em algumas crianças. Através de novas análises dos vídeos de 115 crianças durante a Situação Estranha, Mary Main e Judith Solomon observaram que essas apresentavam comportamentos extremamente estereotipados, além de grande medo do cuidador principal durante o procedimento, sinais esses que não eram observados quando tal cuidador estava ausente. Assim, elas concluíram que era possível organizá-las dentro de um novo padrão de apego: o inseguro desorganizado/desorientado (Main \& Solomon, 1986). Ainda, elas sugeriram que as interações existentes entre infantes que apresentavam tal padrão e seu cuidador não propiciaram aspectos que lhes permitissem organizar uma estratégia de apego.

Segundo Fraley e Shaver (2000), durante muito tempo, a pesquisa com Apego focou na interação cuidador-infante, até que em 1987 Cindy Hazan e Phillip Shaver observaram que era possível transpor os termos do apego infantil para os relacionamentos afetivos na vida adulta, o que acreditamos tenha sido um salto extremamente importante na compreensão da maneira como as pessoas se colocam inicialmente numa relação amorosa. Isso forneceria, exatamente, o elemento de referência, através do qual uma pessoa começaria seus relacionamentos na vida adulta. Hazan e Shaver (1987) conceitualizaram, então, o amor romântico como um processo de apego.

Tais autores utilizaram um questionário no qual havia três frases cabendo ao leitor escolher com qual delas ele concordava mais. Cada uma dessas frases correspondia a um estilo de apego: seguro, evitativo e ansioso/ambivalente. Um dos resultados interessantes encontrados foi que a porcentagem encontrada por Ainsworth e colaboradores de cada padrão de apego permanecia muito próxima da encontrada para a população adulta (Hazan \& Shaver, 1987). Assim, na conclusão desses autores, 
uma vez estabelecido durante a infância, o padrão de apego do indivíduo pode ser levado para o contexto de outras relações interpessoais.

Após a publicação do trabalho de Hazan e Shaver, diversos trabalhos surgiram no intuito de observar o que era próprio de cada estilo dentro de uma relação romântica (ver Belsky, 1997, para uma revisão). Todavia, limitações e críticas ao modelo de Hazan e Shaver surgiram, sendo as mesmas reconhecidas pelos autores. Primeiro devido ao modelo focar apenas uma via da relação, ou seja, a frase estaria organizada psicometricamente apenas para avaliar o modo como o indivíduo se vê (Hazan \& Shaver, 1987). Segundo, pelo fato de que os participantes do estudo eram "forçados" a escolher uma das frases, o que os levariam a ser classificados de forma categórica (Feeney, 2008). Ainda, esse modelo de autoavaliação poderia não ser tão preciso para "extrair" as informações necessárias do participante.

Outras medidas de "papel e caneta" surgiram, como por exemplo, o influente trabalho de Bartholomew e Horowitz (1991), que propôs analisar os estilos de apego como protótipos, em vez de categorias. Eles formularam quatro frases que levaram em consideração o modelo interno do próprio indivíduo e o modelo interno do outro, ideia proposta pelo próprio John Bowlby durante a elaboração da teoria do Apego (Bartholomew \& Horowitz, 1991; Varella, 2007). Além disso, esse trabalho desmembra o estilo evitativo anteriormente proposto para infantes em: evitativo medroso e evitativo rejeitador, resultando em quatro estilos de apego (Barbosa, 2008), o que se aproxima mais da proposta de Main e Solomon (1986) quanto à classificação dos estilos de apego.

Posteriormente, Griffin e Bartholomew (1994) criaram o Questionário dos Estilos das Relações (Relationships Questionnaire Styles). Essa escala, de natureza multi-item, é composta por 30 itens, permitindo avaliar o indivíduo tanto categoricamente quanto dimensionalmente. Ainda, tal escala demonstrou uma maior confiabilidade do que o instrumento proposto em 1991 por Bartholomew e Horowitz (Crowell, Fraley, \& Shaver, 2008).

Atualmente uma medida bastante utilizada para avaliar os estilos de apego é o Questionário de Experiências nas Relações Próximas proposto por Brennan, Clark e Shaver (1998), que defendem a ideia de que os estilos de apego são vistos de forma mais adequada como dimensões e não como categorias, ou seja, considerar um indivíduo como seguro (no sentido categórico), por exemplo, pode sugerir considerá-lo como mais "seguro" do que outro, não levando em consideração variações individuais quando se adota um instrumento categórico.

Diversas publicações têm buscado ver o modo como estilos de apego influenciam aspectos das relações românticas. Por exemplo, o estudo de Simpson (1990) examinou 144 casais e mostrou que indivíduos com estilo de apego seguro possuíam maior satisfação, confiança, comprometimento e maior independência no relacionamento quando comparados com indivíduos com estilo inseguro. No mesmo ano, Collins e Read (1990) 
trabalhando com casais de namorados, observaram que indivíduos com altos escores na dimensão ansiedade relataram angústia sobre pensamentos como ser abandonado ou não ser amado pelo parceiro. Outro estudo de grande repercussão foi o de Kirkpatrick e Hazan (1994), o qual acompanhou, longitudinalmente, 177 casais durante quatro anos. Os resultados mostraram que indivíduos com estilo de apego inseguro foram os que mais frequentemente relataram término de relacionamento uma ou mais vezes durante o período do estudo do que indivíduos com estilo de apego seguro.

Dessa forma, fica clara a possibilidade de relacionar os diferentes estilos de Apego com aspectos importantes no funcionamento das relações românticas, tais como duração e satisfação no relacionamento.

\section{Estilo de apego ideal?}

Incluir os estilos de apego na compreensão das relações românticas remete a uma nova gama de questionamentos. Uma vez que os estudos evidenciam diferenças comportamentais existentes entre os estilos de apego quanto às relações amorosas levaram a questões como: existiria um estilo de apego "ótimo", que favoreceria maior satisfação, e consequentemente sucesso, nas relações românticas? O estilo de apego seguro é "melhor" do que os estilos inseguros?

Para Bowlby (1969/2002), com base no conceito de Ambiente de Adaptação Evolutiva (AAE), os comportamentos hoje expressos por uma espécie foram "projetados" no ambiente em que ela evoluiu e tais comportamentos conferiram uma vantagem para a sobrevivência.

No caso do homem, acredita-se que durante o Pleistoceno, que teve início a cerca de dois milhões e durou, aproximadamente, até 10 mil anos atrás, ocorreram pressões seletivas importantes, sendo a arquitetura da mente humana provavelmente moldada nesse período (Izar, 2009).

Considerando que as condições ambientais do AAE eram extremamente hostis, o infante que mais se vinculasse emocionalmente ao cuidador principal e recebesse cuidado sensível e responsivo teria uma maior chance de sobreviver a tais condições (Bowlby, 1969/2002), o valor adaptativo do estilo de apego seguro apresentava evidências mais conclusivas para os pesquisadores. Todavia, a dificuldade residia na interpretação de um valor adaptativo para os estilos de apego inseguro.

Belsky (1997) trouxe uma proposta para a interpretação dos estilos de apego baseado no AAE, utilizando uma perspectiva evolucionista. Estes teriam evoluído porque aumentariam a aptidão reprodutiva do portador de acordo com certas condições ecológicas, ou seja, o alvo das pressões seletivas para o comportamento de apego estaria mais relacionado 
com o sucesso reprodutivo do que propriamente com a sobrevivência do infante. $O$ estilo de apego seguro evoluiu baseado no cuidado sensível dado pelo cuidador ao infante em virtude das condições socioambientais favoráveis. Isso resultou na construção de um modelo mental positivo pelo infante fazendo-o perceber o ambiente social como favorável e que as pessoas eram confiáveis, devido às relações serem recompensadoras e estáveis. Na idade reprodutiva, o indivíduo adotaria então uma estratégia que enfatizasse o esforço parental. $O$ estilo de apego inseguro ansioso teria evoluído como resultado do cuidado não responsivo dos pais e na permanência desses indivíduos no grupo sem reproduzirem-se. Tal permanência seria "paga" com a ajuda no cuidado com irmãos mais novos. Esse estilo de apego resultaria no comportamento "ajudante de ninho", ou seja, indivíduos direcionariam comportamentos de cuidado e proteção a parentes, viabilizando seu sucesso reprodutivo através da reprodução de indivíduos aparentados que teriam sido ajudados por eles. Por último, o estilo inseguro evitativo teria evoluído em virtude de um ambiente físico e social bastante hostil, em conjunto com um cuidador principal insensível e rejeitador. Devido a essas condições, os indivíduos evitativos tenderiam a não confiar nas pessoas, e as possíveis relações não seriam nem gratificantes e nem duradouras, adotando assim estratégias reprodutivas oportunísticas, as quais enfatizariam no esforço de acasalamento, ou seja, investimento em quantidade de parceiros (Belsky, 1997; Belsky \& Simpson, 2008). Nenhuma previsão foi feita por Belsky (1997) no que se refere ao estilo de apego inseguro desorganizado/desorientado.

As formas iniciais de interação seriam importantes, portanto, no direcionamento que o indivíduo vai estabelecendo no que se referem às suas interações amorosas na vida adulta. As relações iniciais de apego, vistas também como uma consequência dos ambientes nos quais os indivíduos estão inseridos, são utilizadas como referenciais no momento de interagir com parceiros amorosos posteriormente (Hazan \& Shaver, 1994). Tendo isso em mente, podemos investigar o motivo pelo qual alguns indivíduos envolvem-se emocionalmente mais do que outros, bem como algumas relações românticas duram mais do que outras.

Escolhas para a vida toda? Adoção de estratégias reprodutivas

É comum observarmos que algumas pessoas estabelecem relacionamentos mais curtos, enquanto outras, relacionamentos duradouros, que persistem até por toda a vida. Na perspectiva evolucionista, esses tipos de relacionamento traduzem o que chamamos de estratégias reprodutivas de curto e longo prazo, atualmente alvo constante de pesquisas. 
Buss e Schmitt (1993) propuseram em sua Teoria das Estratégias Sexuais, que a adoção de estratégias de curto ou longo prazo seria realizada de acordo com os custos e benefícios associados. Eles propõem que durante o AAE homens e mulheres desenvolveram mecanismos psicológicos evoluídos, para resolverem diferentes problemas adaptativos, como sobrevivência e reprodução. Por exemplo, mulheres deveriam ser sensíveis para perceberem parceiros capazes de obter e investir recursos na prole, sendo um relacionamento de longo prazo mais vantajoso para elas. Já para o homem, um dos problemas a serem resolvidos é ter a certeza de que a prole na qual está investindo é sua. Caso não seja, o custo para ele será elevado, tornando os relacionamentos de curto prazo mais vantajosos, pois as chances de fertilizar um maior número de parceiras aumentariam, com um baixo investimento (Buss \& Schmitt, 1993).

$\mathrm{Na}$ adoção de estratégias entre os sexos, cada indivíduo busca maximizar seu sucesso reprodutivo, extraindo a maior quantidade de benefícios possíveis do parceiro. As fêmeas de mamíferos investem pesadamente na prole, devido à gestação e lactação, não sendo possível, durante esse período, investir em outra prole. Já para os machos, tal investimento fisiológico não é obrigatório, levando-os a contribuir, quase exclusivamente com o esperma (Geary, Vigil, \& Byrd-Craven, 2004).

A adoção de uma estratégia reprodutiva em função do investimento que cada um dos sexos faz na prole pode nos auxiliar a compreender padrões comportamentais mais comuns para homens e mulheres, no que se refere à escolha do parceiro. Como já visto, mulheres investem acentuadamente na prole e isso as torna o sexo mais seletivo na escolha do parceiro. Já homens, cujo investimento é baixo e opcional na prole, tornam-se o sexo menos seletivo e o qual compete para ter o acesso à parceira (Trivers, 1972).

Entretanto, um determinado ambiente não permanece com as condições ecológicas estáveis ao longo do tempo e os indivíduos não se comportam de forma igual. Com base nisso, Gangestad e Simpson (2000) propõem a Teoria das Estratégias Pluralísticas, demonstrando que nem sempre homens preferem estratégias de curto prazo, nem mulheres optam pelo longo prazo. Esse modelo foca no porquê da variabilidade de estratégias sexuais existentes dentro de cada gênero, sem contradizer a importância das diferenças existentes entre gêneros na escolha. Os autores afirmam que a seleção natural teria gerado um conjunto flexível de estratégias e táticas reprodutivas, que seriam "ativadas" condicionalmente a partir da capacidade dos indivíduos detectarem variações de sinais socioambientais. Ainda, sugerem que essas estratégias reprodutivas são em função da busca por bons genes e na busca de um bom parceiro e provedor de recursos.

Verificando como a ecologia local de um determinado ambiente de criação reflete no desenvolvimento dos estilos de apego e como es- 
tes influenciam na adoção de um tipo de estratégia reprodutiva, Schmitt (2008) pesquisou, em 56 nações, se maiores ou menores níveis de estresse ecológico e escassez de recursos seriam preditores de estilo de apego inseguro e se em culturas onde estressores ambientais e reprodutivos são relativamente elevados, tanto homens e mulheres tenderiam a se engajar em estratégias de curto prazo. Os resultados mostraram que em culturas com menores índices de desenvolvimento humano (IDH), indivíduos tenderam a desenvolver estilo de apego rejeitador. Também, culturas com elevada taxa de mortalidade e elevados índices de estresse social mostraram que homens e mulheres são similares na adoção de estratégias reprodutivas de curto prazo. Dentre as conclusões, o autor enfatiza a função das adaptações psicológicas em "sintonizar" com a ecologia local durante o ambiente de desenvolvimento do indivíduo para facilitar a organização de uma estratégia reprodutiva. Ainda, dependendo desse ambiente, homens e mulheres podem adotar estratégias reprodutivas similares ou distintas (Schmitt, 2008).

\section{Estudos no Brasil}

Estudos empíricos abordando amor vêm crescendo no Brasil, com ênfase na validação de escalas e abordando variáveis envolvidas na satisfação do relacionamento.

Dentre esses estudos, Cassepp-Borges e Teodoro (2007) investigaram as propriedades psicométricas da Escala Triangular do Amor de Sternberg (ETAS) entre universitários no sul do Brasil. A ETAS está organizada em três subescalas: intimidade, paixão e decisão/comprometimento (cada uma com 15 itens), para, de forma conjunta, mensurar o amor. Os autores concluíram que, de acordo com os resultados obtidos, a ETAS se ajusta ao contexto no qual foi aplicada.

O estudo de Norgren, Souza, Kaslow, Hammerschmidt e Sharlin (2004) também avaliou a satisfação no relacionamento de 38 casais com mais de 20 anos de relacionamento. Eles compararam casais satisfeitos e insatisfeitos, verificando que a satisfação no relacionamento aumentava quando existia proximidade, estratégias adequadas para solução de problemas, boa habilidade de comunicação e satisfação com o status econômico.

Hernandez e Oliveira (2003) vêm relacionando amor com o grau de satisfação dentro da relação. Nesse estudo, 146 casais responderam a escalas que mediam satisfação dentro da relação e componentes do amor. Os autores concluem que o componente intimidade comunicativa, seguido de excitação física, são os componentes que mais proporcionam satisfação dentro de um relacionamento. 
Andrade, Garcia e Cano (2009) verificaram quais elementos eram preditores de satisfação global em relacionamentos românticos. Utilizando a ETAS e escalas que avaliam satisfação sexual e qualidade de vida, eles afirmam que intimidade, paixão e comprometimento, juntamente com aspectos positivos da satisfação sexual e satisfação com a vida, são preditores globais de satisfação em relações românticas.

Paralelo a esses estudos, a abordagem evolucionista no estudo do comportamento humano vem se consolidando. O projeto Instituto do Milênio em Psicologia Evolucionista (2005-2009) permitiu o estabelecimento dessa nova área de análise do comportamento humano. Questões sobre investimento reprodutivo e parental puderam ser respondidas e outras novas foram lançadas, utilizando as propostas de Gangestad e Simpson (2000) e de Schmitt (2005), com resultados bastante robustos. Varela (2007) verificou a relação de estilos de apego e orientação sociossexual, encontrando que o estilo rejeitador era preditor de uma sociossexualidade irrestrita, tanto para homens quanto para mulheres. Vieira, Silveira, Vieira e Prado (2010), comparando o investimento materno em diferentes contextos, observaram que mães com pior qualidade no ambiente familiar durante a infância adotaram uma estratégia reprodutiva quantitativa, sendo o inverso verdadeiro. Esses resultados demonstram que mecanismos fisiológicos e a expressão de estratégias reprodutivas são organizados de acordo com o ambiente no qual o indivíduo está inserido. Ainda, Castro e Lopes (2011), investigando características preferidas por homens e mulheres tanto em relacionamentos de longo prazo, quanto de curto prazo, observaram que homens priorizavam traços físicos para relações de curto prazo, mas à medida que o investimento no relacionamento aumentava, traços pessoais ganhavam importância. Mulheres em relações de curto prazo priorizavam traços físicos e pessoais, ao passo que em relações de longo prazo, elas priorizavam parceiros que fossem capazes de adquirir recursos. Desse modo, é possível perceber que a medida que o investimento num relacionamento romântico aumenta, o nível de seletividade aumenta em ambos os sexos.

\section{Considerações Finais}

Através da revisão desses estudos abordando amor, apego e estratégias sexuais, sugerimos que estes temas sejam estudados de forma articulada, e propomos que isso seja feito da seguinte maneira: a associação que o infante estabelece com o seu cuidador principal é essencial à sua sobrevivência, e reflete não só a disponibilidade desse cuidador como também as condições socioecológicas nas quais o infante se encontra. Esse estabelecimento de vínculo inicial servirá de referencial na maneira 
como o indivíduo irá formar e manter as relações interpessoais ao longo da vida, incluindo as relações românticas. A interação desses fatores (o apego inicial e a experiência de amar) irá culminar na adoção de estratégias sexuais que serão um reflexo destes e também condizentes com as condições socioecológicas nas quais o indivíduo se encontra durante a escolha de parceiros e na manutenção ou não de um relacionamento.

Tal associação ainda não foi completamente comprovada empiricamente. Se o amor é um fenômeno multidimensional, cuja experiência emocional varia de acordo com o contexto, indicamos estudos que busquem avaliar quais são os melhores protótipos que definem amor no ambiente em que o indivíduo está inserido, para assim verificarmos se esse ambiente molda tal experiência emocional como positiva ou negativa.

Também, questões abordando variáveis fisiológicas, como por exemplo, o perfil de secreção hormonal dos diferentes estilos de apego, seriam potenciais caminhos de investigação. Se indivíduos com o estilo de apego ansioso/ambivalente tendem a direcionar comportamentos de cuidado, teriam eles maiores níveis basais de ocitocina e prolactina (hormônios relacionados com comportamentos afiliativos e de cuidado com a prole) circulantes quando comparados aos outros estilos? Uma vez que apresentam um maior distanciamento dentro das relações interpessoais, indivíduos com o estilo evitativo apresentariam uma menor reatividade na liberação de cortisol (já que este hormônio está relacionado com eventos de estresse) após o término de um relacionamento romântico?

Por último, verificar se os estilos de apego influenciam na forma como o indivíduo "enxerga" amor e como isso resulta na adoção de uma estratégia reprodutiva de curto ou longo prazo é uma interessante forma de integrar perspectivas biológicas e sociais em um dos assuntos que é de grande interesse a todos nós: as relações românticas. Sugestões teóricas e os resultados obtidos no nosso país são encorajadores para seguirmos nessa área de pesquisa que ainda possui diversas incógnitas, podendo resultados futuros ser aplicados, inclusive, para orientação de casais, contribuindo para a satisfação dentro dos relacionamentos românticos. 


\section{The evolutionary perspective on romantic relationships}

Abstract: Romantic relationships have a strong impact in our lives. However, an integrative approach of biological and social perspectives on this subject can lead to a better comprehension of the reasons for long or short relationships. This work aimed to contribute to Brazilian literature about this topic with a review on concepts about Love, Attachment Theory and Sexual Strategies based on an evolutionary perspective. The observed gaps on the topic and the results obtained by some research in our country are encouraging to maintain this theoretical integration at this research field that could be applied in couples counseling, contributing to satisfaction within romantic relationships.

Keywords: Love. Attachment Theory. Sexual Strategies. Evolutionary Perspective.

\section{La perspective évolutionniste sur les relations romantiques}

Résumé: Les relations amoureuses ont un fort impact sur nos vies quotidiennes. Cependant, pour comprendre pourquoi certaines relations amoureuses durent plus longtemps que d'autres, nous devrons intégrer les informations biologiques et sociales. Ce texte vise examiner de façon critique les concepts d'amour, de la théorie de l'attachement et des stratégies sexuelles du point de vue de l'évolution naturelle, en attendant contribuer à la littérature scientifique en Brésil. Les lacunes sur le thème, associées aux résultats de recherche dans notre pays sont encourageantes pour la maintenance de l'intégration théorique dans ce domaine de recherche qui peut être appliquée aux orientations psychologiques des couples, contribuant à la satisfaction des relations amoureuses.

Mots-clés: Amour. Théorie de l'attachement. Stratégies sexuelles. Perspective évolutionniste.

\section{La perspectiva de la evolución en las relaciones románticas}

Resumen: Las relaciones amorosas tienen un fuerte impacto en nuestra vida cotidiana. Sin embargo, la integración de los factores biológicos y sociales nos ayudan a entender, de modo consistente, por qué algunas relaciones duran más que otras. El objetivo de este presente estudio es revisar críticamente los conceptos de Amor,Teoría del Apego y Estrategias Sexuales desde una perspectiva evolutiva, a fin de contribuir con esta revisión para la literatura en Brasil. Las lagunas observadas en la temática, 
bien como los resultados de algunas investigaciones en nuestro país, apuntan para el mantenimiento de la integración teórica en esta área de investigación, que puede ser aplicada junto a parejas, contribuyendo para la satisfacción en las relaciones románticas.

Palabras-clave: Amor. Teoría del Apego. Estrategias Sexuales. Perspectiva Evolutiva.

\section{Referências}

Ainsworth, M. D. S., Blehar, M. C., Waters, E., \& Wall, S. (1978). Patterns of attachment: A psychological study of the strange situation. Hillsdale, NJ: Erlbaum.

Alencar, J. (1997). Cinco minutos. Porto Alegre, RS: L \& PM Pocket. (Trabalho original publicado em 1860)

Andrade, A. L., Garcia, A., \& Cano, D. S. (2009). Preditores da satisfação global em relacionamentos românticos. Psicologia: Teoria e Prática, 11(3), 143-156.

Barbosa, D. R. (2008). Império do Amor Romântico: diferenças culturais e sexuais em casais de noivos no Brasil e na Itália (Tese de Doutorado). Universidade de São Paulo, São Paulo.

Bartholomew, K., \& Horowitz, L. M. (1991). Attachment styles among young adults: A test of a four-category model. Journal of Personality and Social Psychology, 61(2), 226-244.

Beall, A. E., \& Sternberg, R. J. (1995). The social construction of love. Journal of Social and Personal Relationships, 12(3), 417-438.

Belsky, J. (1997). Attachment, mating, and parenting: An evolutionary interpretation. Human Nature, 8(4), 361-381.

Belsky, J., \& Simpson, J. A. (2008). Attachment theory within a modern evolutionary framework. In J. Cassidy \& P. R. Shaver (Eds.), Handbook of attachment: Theory, research, and clinical applications (pp. 131-157). New York, NY: Guilford.

Berscheid, E. (2006). Searching for the meaning of "Love". In R. J. Sternberg \& K. Weis (Eds.), The new psychology of love (pp. 171-183). New Haven, CT: Yale University Press. 
Bowlby, J. (1958). The nature of the child's tie to his mother. International Journal of Psycho-Analysis, 39, 350-373.

Bowlby, J. (1998). Apego e perda: Vol. III. Perda: tristeza e depressão (2a ed., V. Dutra, trad.). São Paulo, SP: Martins Fontes. (Trabalho original publicado em 1980)

Bowlby, J. (2002). Apego e perda: Vol I. Apego (3a ed., Á. Cabral, trad.). São Paulo, SP: Martins Fontes. (Trabalho original publicado em 1969)

Bowlby, J. (2004). Separação: angústia e raiva (4a ed., L. Regenberg, O. S. da Mota \& M. Hegenberg, trads.). São Paulo, SP: Martins Fontes. (Trabalho original publicado em 1973)

Brennan, K. A., Clark, C. L., \& Shaver, P. R. (1998). Self-report measurement of adult attachment: An integrative overview. In J. A. Simpson \& W. S. Rholes (Eds.), Attachment theory and close relationships (pp. 46-76). New York, NY: Guilford.

Buss, D. (1988). Love acts: The evolutionary biology of love. In R. J. Sternberg \& M. L. Barnes (Eds.), The psychology of love (pp. 100-118). New Haven, CT: Yale University Press.

Buss, D. M., \& Schmitt, D. R. (1993). Sexual strategies theory: An evolutionary perspective on human mating. Psychological Review , 100, 204-232.

Cassepp-Borges, V., \& Teodoro, M. L. M. (2007). Propriedades psicométricas da versão brasileira da Escala Triangular do Amor de Sternberg. Psicologia: Reflexão e Crítica, 20(3), 513-522.

Castro, F. N., \& Lopes. F. A. (2011). Romantic preferences in brazilian undergraduate students: From the short term to the long term. Journal of Sex Research, 47, 1-7.

Chisholm, J. S. (1996). The evolutionary ecology of attachment organization. Human Nature, 7(1), 1-38.

Collins, N. L., \& Read, S. J. (1990). Adult attachment, working models, and relationship quality in dating couples. Journal of Personality and Social Psychology, 58(4), 644663.

Collins, N. L., \& Feeney, B. C. (2000). A safe haven: An attachment theory Perspective on support seeking and caregiving in intimate relationships. Journal of Personality and Social Psychology, 78(6), 1053-1073.

Crowell, J. A., Fraley, R. C., \& Shaver, P. R. (2008). Measurement of individual differences in adolescent and adult attachment. In J. Cassidy \& P. R. Shaver (Eds.), Handbook 
of attachment: Theory, research, and clinical applications (pp. 599-634). New York, NY: Guilford.

Feeney, J. A. (2008). Adult romantic attachment: Developments in the study of couple relationships. In J. Cassidy \& P. R. Shaver (Eds.), Handbook of attachment: Theory, research, and clinical applications (pp. 456-481). New York, NY: Guilford.

Fehr, B. (1988). Prototype analysis of the concept of love and commitment. Journal of Personality and Social Psychology, 55(4), 557-579.

Fehr, B. (2001). The status of theory and research on love and commitment. In G. J. O. Fletcher \& M. S. Clark (Eds.), Blackwell handbook of social psychology: Interpersonal process (pp. 331-356). Oxford: Blackwell.

Fehr, B. (2006). A prototype approach to studying love. In R. J. Sternberg \& K. Weis (Eds.), The new psychology of love (pp. 225-246). New Haven, CT: Yale University Press.

Fehr, B., \& Russell, J. A. (1991). The concept of love viewed from a prototype perspective. Journal of Personality and Social Psychology, 60(3), 425-438.

Fisher, H. (2006). The drive to love: The neural mechanism for mate selection. In R. J. Sternberg \& K. Weis (Eds.), The new psychology of love (pp. 87-115). New Haven, CT: Yale University Press.

Fisher, H., Aron, A., Mashek, D., Hainfang, L., \& Brown, L. L. (2002). Defining the brain systems of lust, romantic attraction, and attachment. Archieves of Sexual Behavior, 31(5), 413-419.

Fraley, R. C., \& Shaver, P. R. (2000). Adult romantic attachment: Theoretical developments, emerging controversies, and unanswered questions. Review of General Psychology, 4, 132-154.

Gangestad, S. W., \& Simpson, J. A. (2000). The evolution of human mating: Trade-offs and strategic pluralism. Behavioral and Brain Sciences, 23, 573-644.

Geary, D. C., Vigil, J., \& Byrd-Craven, J. (2004). Evolution of human mate choice. Journal of Sex Research, 41(1), 27-42.

George, C., \& West, M. (2001). The development and preliminary validation of a new measure of adult attachment: The adult attachment projective. Attachment \& Human Development, 3, 30-61. 
Gouveia, V. V., Fonseca, P. N., Cavalcanti, J. P. N., Diniz, P. K. C., \& Dória, L. C. (2009). Versão abreviada da Escala Triangular do Amor: evidências de validade fatorial e consistência interna. Estudos de Psicologia (Natal), 14(1), 31-39.

Griffin, D., \& Bartholomew, K. (1994). Models of the self and other: Fundamental dimensions underlying measures of adult attachment. Journal of Personality and Social Psychology, 67(3), 430-445.

Harlow, H. F. (1958). The nature of love. American Psychologist, 13, 673-685.

Hazan, C., \& Shaver, P, R. (1987). Romantic love conceptualized as an attachment process. Journal of Personality and Social Psychology, 52(3), 511-524.

Hazan, C., \& Shaver, P. R. (1994). Attachment as an organizational framework for research on close relationships. Psychological Inquiry, 5(1), 1-22.

Hegi, K. E., \& Bergner, R. M. (2010). What is love? An empirically-based essentialist account. Journal of Social and Personal Relationships, 27(5), 620-636.

Hendrick, C., \& Hendrick, S. S. (1986). A theory and method of love. Journal of Personality and Social Psychology, 50(2), 392-402.

Hendrick, C., \& Hendrick, S. S. (2006). Styles of romantic love. In R. J. Sternberg \& K. Weis (Eds.), The new psychology of love (pp. 149-170). New Haven, CT: Yale University Press.

Hernandez, J. A. E., \& Oliveira, L. M. B. (2003). Os componentes do amor e a satisfação. Psicologia: Ciência e Profissão, 21, 58-69.

Izar, P. (2009). Ambiente de adaptação evolutiva. In E. Otta \& M. E. Yamamoto (Orgs.), Fundamentos da psicologia: psicologia evolucionista (pp. 22-32). Rio de Janeiro, RJ: Guanabara Koogan.

Kirkpatrick, L. A., \& Hazan, C. (1994). Attachment styles and close relationships: A four-year prospective study. Personal Relationships, 1, 123-142.

Lee, J. A. (1973). The colors of love: An exploration of the ways of loving. Don Mills, Canada: New Press.

Lee, J. A. (1988). Love-styles. In R. J. Sternberg \& M. L. Barnes (Eds.), The psychology of love (pp. 38-67). New Haven, CT: Yale University Press.

Madey, S. F., \& Rodgers, L. (2009). The effect of attachment and sternberg's triangular theory of love on relationships satisfaction. Individual Differences Research, 7(2), 76-84. 
Main, M., \& Solomon, J. (1986). Discovery of a disorganized/disoriented attachment pattern. In T. B. Brazelton \& M. W. Yogman (Eds.), Affective development in infancy (pp. 95-124). Norwood, NJ: Ablex.

Mikulincer, M., \& Shaver, P. R. (2008). Adult attachment and affect regulation. In J. Cassidy \& P. Shaver (Eds.), Handbook of attachment: Theory, research, and clinical applications (pp. 503-531). New York, NY: Guilford Press.

Norgren, M. B. P., Souza, R. M., Kaslow, F., Hammerschmidt, H., \& Sharlin, S. A. (2004). Satisfação conjugal em casamentos de longa duração: uma construção possível. Estudos de Psicologia (Natal), 9(3), 575-584.

Rosch, E. (1975). Cognitive representations of semantic categories. Journal of Experimental Psychology, 104(3), 192-233.

Rubin, Z. (1970). Measurement of romantic love. Journal of Personality and Social Psychology, 16(2), 265-273.

Schmitt, D, P. (2005). Sociosexuality from Argentina to Zimbabwe: A 48-nation study of sex, culture, and strategies of human mating. Behavioral and Brain Sciences, 28, 247-311.

Schmitt, D. P. (2008). Evolutionary perspectives on romantic attachment and culture. How ecological stressors influence dismissing orientations across gender and geographies. Cross-cultural Research, 42, 220-247.

Shaver, P. R., \& Mikulincer, M. (2006). A behavioral systems approach to romantic love relationships: Attachment, caregiving, and sex. In R. J. Sternberg \& K. Weis (Eds.), The new psychology of love (pp. 35-64). New Haven, CT: Yale University Press.

Simpson, J. A. (1990). Influence of attachment styles on romantic relationships. Journal of Personality and Social Psychology, 59(5), 971-980.

Sternberg, R. J. (1986). A triangular theory of love. Psychological Review, 93(2), 119-135.

Sternberg, R. J. (1988). The triangle of love. New York, NY: Basic Books.

Sternberg, R. J. (1997). Construct validation of a triangular love scale. European Journal of Psychology, 27, 313-335.

Sternberg, R. J. (2006). A duplex theory of love. In R. J. Sternberg \& K. Weis (Eds.), The new psychology of love (pp. 184-199). New Haven, CT: Yale University Press. 
Sternberg, R. J., \& Grajek, S. (1984). The nature of love. Journal of Personality and Social Psychology, 47(2), 312-329.

Sternberg, R. J., \& Barnes, M. L. (1985). Real and ideal others in romantic relationships: Is four a crowd? Journal of Personality and Social Psychology, 49(6), 1586-1608.

Trivers, R. L. (1972). Parental investment and sexual selection. In B. Campbell (Ed.), Sexual selection and the descent of man 1871-1971 (pp. 136-207). Chicago IL: Aldine Publishing Company.

Varella, M. A. C. (2007). Variação individual nas estratégias sexuais: alocação de investimentos parentais e pluralismo estratégico (Dissertação de Mestrado). Universidade de São Paulo, São Paulo.

Vieira, V., Silveira, L. C., Vieira, M. L., \& Prado, A. B. (2010). Investimento materno e história reprodutiva de mães residentes em contextos com diferentes graus de urbanização. Psicologia: Teoria e Pesquisa, 26(2), 331-340. 
Victor Kenji M. Shiramizu, Departamento de Fisiologia, Programa de Pós-graduação em Psicobiologia. Endereço para correspondência: Centro de Biociências, Universidade Federal do Rio Grande do Norte - UFRN - Campus Universitário. Caixa Postal 1511, Lagoa Nova.CEP:59078-970. Endereço eletrônico: victorshiramizu@gmail.com

Fívia de Araújo Lopes, Departamento de Fisiologia, Programa de Pós-graduação em Psicobiologia, Universidade Federal do Rio Grande do Norte. Endereço para correspondência: Centro de Biociências, Universidade Federal do Rio Grande do Norte - UFRN - Campus Universitário. Caixa Postal 1511, Lagoa Nova. CEP: 59078-970. Endereço eletrônico: fivialopes@gmail.com

Recebido: 26/06/2012

Aceito: 04/03/2013 